\title{
The Identity of Objects: Form \& Nature in Digital Museums
}

\author{
Jason T. Hewitt \\ Department of Information Studies, University of California Los Angeles, USA
}

\begin{abstract}
Reconciling Justus Buchler's theory of natural complexes with the Peircean triadic categorial schema, a theory of semiotic radiance is articulated that elaborates the nature of identity with regard to informatic control over objects in a museum collection. The model is deployed in the context of Edwina Taborsky's description of the historical transformation of the cultural syntax of museums. It is argued that the pattern of transformation is not random, but rather follows a specific and recognizable pattern. This pattern is consistent with a general trend in culture, identified by Heidegger, that becomes particularly problematic in its later stages. A theory of the commons derived from Hardt and Negri is articulated that looks to regenerate the space of the museum with regard to its informatic structures in order to renegotiate humanism in terms of a liberation ethic. The rubric of fundamental informatics is borrowed from Toru Nishigaki to describe the inquiry that pursues that end.
\end{abstract}

Keywords: semiotics, pragmatism, fundamental informatics, general informatics, museum informatics, museology, ontology of information, information ethics

\section{Providing Integrities}

Justus Buchler has argued for an understanding of nature as the availability of orders. If nature is such availability, then the "natural" would be that which constitutes or is situated within or by the orders available. Buchler describes any natural that can be discriminated in this sense as a natural complex: "Whatever is, in whatever way, is a natural complex." (Buchler, 1990, p. 1) "Every complex is an order and belongs to an order of complexes. Thus orders are inclusive and belong to more inclusive orders." (p. 93) A complex, being made up of other complexes (“...any complex is a complex of complexes." (p. 2)), provides order and context for its constituent complexes. This is in keeping with nature and is also an expression of it:

The idea of nature, in so far as it means not merely the common factor of all 'natures' but the source of all that is, implies the perennial conceivability of complexes more inclusive than any that is dealt with. Nature in the barest sense is the presence and availability of complexes. It is the provision and determination of traits_-providingness ... but not providence, not providentness (p. 3).

A complex is itself, and is, as such, the framing context for that which constitutes it. In fact, it is itself only insofar as it is and provides such a framework.

An order is a sphere of (or for) relatedness. It is what 'provides' extent, conditions, and kinds of relatedness. Despite the fact that in its multiplicity of traits an order is not 'internally' limited, as an order among orders it is precisely what limits (p. 95).

The variety of situated frameworks provides the insight to generalizing continuity that allows for a complex to constitute another, according to whatever means of relation, in and as each particular framework, while the total coherence of these frameworks in their operational providingness provides for the multiplicity of difference.

Buchler's nature might be called "pluralistic" in William James' sense. (James, 1996) "The integrity of a complex belongs to it not in spite of but because of its multiplicity and relatedness." (Buchler, p. 24) This may indicate that the source of value for a complex may not reside in its uniqueness, originality, or irreplaceability, but rather in the nature or quality of its presence, its radiant semiosis. Moreover, objects of inquiry are themselves complexes, meaning that our line of inquiry or analysis is naturally non-terminating in the least, if not ampliative: 
The idea of ontological simples, of irreducible components of nature, implies belief in absolute termini of analysis. Its appeal is not hard to detect. It seems to yield the assurance of a 'foundation' for knowledge, and a stable or reliable foundation. It seems to provide 'real' or 'ultimate' elements. It seems to certify that familiar things, if they do not dissolve, do not dissolve into nothing and are not lost (p. 17).

The idea of a simple is a complex that reifies identity in order to frame a certain integrity of a complex such that overall contour need not be at issue. This allows the integrity to be taken as sign within the context of a discursive system, which is to say as a sign possessed of a rational 'meaning.' Because the contour of a complex is ultimately ordinally open, the framing of an integrity makes cognizable what would otherwise be a surplus of meaning-an exuberant radiance in Bataille's terms that is "contained" in the context of power through the promulgation of a dialectic.

Insofar as a complex is itself, it is also just itself as that particular complex.

Whatever the boundaries or limits of complexes may happen to be, whatever may be the conditions under which these limits obtain, wherever these limits may lie, any complex has just that status, just the relations, just the constitution that it has. This is its integrity, that in which its being 'a' complex and 'that' complex consists (pp. 21-22).

The integrity of a complex is itself complicated, however, and is related to the contour and identity of a complex.

The integrity of a complex is always conditional, in the sense that it is minimally determined by the location of the complex in this or that order of complexes. A complex has an integrity for each of its ordinal locations. The continuity and totality of its locations, the interrelation of its integrities, is the contour of the complex. The contour is itself an integrity, the gross integrity of that which is plurally located, whether successively or simultaneously. A contour is the integrity of a complex not in so far as the complex transcends all orders but in so far as it belongs to many orders. The identity of a complex is the continuous relation that obtains between the contour of a complex and any of its integrities (p. 22).

\section{Contours of Radiant Semiosis}

The complex presents itself as a radiant semiosis: following C.S. Peirce's categories, the contour of a complex is its Firstness, the integrity its Secondness, and the identity its Thirdness. Identity as the mediation between the contour and integrity of a complex is, perhaps, a surprising stance. Identity, as Third, taken as First for a new semiotic triad, can give rise to the illusion of a sign of pre-determined "meaning" being available independent of the specific integrity and thus give rise to the Platonic fallacy. The existent does not participate in the form, but rather the form emerges in, as, and out of an encounter with the complex-which is to say as the recognition of the identity of the differential integrity of a complex's contour. In this sense, the identity of a complex can be seen as either a discernment or a judgment, the understanding or the ascription of identity as the significance of the integrity of a complex. Identities are discerned as a way to order experience: integrities are related to contours in order to filter the noise of radiant natural semiosis. "Discriminations are, so to speak, framings of complexes from the welter of complexes." (p. 22)

The identity of a complex is, then, our take on the radiant presence of a complex, the frame through which we come to an understanding in encounter. Going beyond Buchler's terminology, the collection of such frames could be said to be the total framework (thinking on analogy with the term "meshwork") by means of which we produce our identity through the providing of integrities in and as the full contour of our own existence. In relation to other complexes, however, we are in the position of providing the encounter that mediates the integrity as identity for an object. The human being responds semiotically to the encounter with other complexes:

The process of discriminating, framing, selecting is the pulse of human utterance.... Depending upon which essential aspect of the human process is emphasized, utterance may be seen 
as 'production' or 'judgment.' Man [sic] produces (a) by acting in relation to the integrities among which he finds himself, (b) by contriving new integrities, and (c) by propositionally structuring integrities in order to affirm or test his suspicions. He is the creature that judges the complexes of nature by producing in these three modes (p. 23).

These three forms of production can be understood as three kinds of semiotic response to the semiotic presence of other complexes: $(a)$ is a response of the contour in Firstness, $(b)$ is a response of the integrity in Secondness, and $(c)$ is a response from identity in Thirdness. We here understand identity as a mediation of integrity and contour. The identity in Thirdness responds by propositionally structuring integrities because what is at stake is the discernment or judgment of the identity of the other, which in turn puts at stake the relation of the contour and the integrity of self that makes possible the production of the discerning or judging self in and as the identity of the human complex. In other words, what is at stake in encounter is the framework of experience by which we articulate our subjectivization, and this in the sense that we take up our experience as knowing subjects discerning natural complexes forming not concepts that reference, or ideas that give a picture, but frames that shape encounter by allowing the natural semiotic radiance of nature - that is, of a natural complex-to inform us in such a way that we can respond in kind.

When this framework of basic encounter itself becomes the object of socialization, by being taken as the object of discursive reference and/or by the positive repositioning of the thetic in the dialectic that clarifies the integrous in the production of the virtual judgment of identity so as to sever excess while extracting value in and from the rational, the framework itself, as a complex, may become dominant and heavily reified due to its lack of contact with the dialectic negative, which is the grounding contour of Firstness. In that case, the sign's meaning is always already determinate, pre-articulated, given, in an inversion that would make the sign appear to refer to identity-an inversion which renders all specific meaning synthetic, interchangeable and virtual, thus derealizing experience and making any and all Secondness seemingly arbitrary, apparently based on the closure of a dialectic of power rather than on an expression of the integrity of natural experience.

Martin Heidegger pointed to this as the source of the alienation and dehumanization that were felt as a result of the great leaps in technology in the twentieth century:

Enframing means the gathering together of that setting-upon which sets upon man [sic], i.e., challenges him forth, to reveal the real, in the mode of ordering, as standing-reserve. Enframing means that way of revealing which holds sway in the essence of modern technology and which is itself nothing technological... (Heidegger, 1977, pp. 20-21).

The danger that Heidegger wants to point to is not that technology is going to take over the world, as in so many of our dystopian fantasies, but just the opposite, keeping with the existential insight at the heart of many of those anti-technological dystopian visions: that we may lose control of our own experience. The irony is glaring: through the rationalization of experience meant to sustain it, we lose experience.

Since destining at any given time starts man on a way of revealing, man, thus under way, is continually approaching the brink of the possibility of pursuing and pushing forward nothing but what is revealed in ordering, and of deriving all his standards on this basis. Through this the other possibility is blocked, that man might be admitted more and sooner and ever more primally to the essence of that which is unconcealed and to its unconcealment, in order that he might experience as his essence his needed belonging to revealing.... As soon as what is unconcealed no longer concerns man even as object, but does so, rather, exclusively as standing-reserve, and man in the midst of objectlessness is nothing but the orderer of the standing-reserve, then he comes to the very brink of a precipitous fall; that is, he comes to the point where he himself will have to be taken as standing-reserve. Meanwhile man, precisely as the one so threatened, exalts himself to the posture of lord of the earth (pp. 26-27). 
If subjectivization emerges in the formation of identities through the encounter of integrities as signs for an open-ended contour, then the production of meaning as standing-reserve, as the encounter with fixed identities, is, in fact, the self-alienation of the human from the humane, the contour that is expressed in our various integrities and subjectivities.

\section{The Cultural Syntax of Museums}

Edwina Taborsky describes the historical evolution of the museum in terms of the manner in which it takes up, as part of a sociocultural system, the objects with which it inter-acts. The evolution she points to is consistent with trends described elsewhere. (Foucault, 1972) (McSherry, 2001, p. 41) Her argument is that the museum, and museum-making cultures, are constituted by a specific cultural syntax that produces similar object-relations in the museum system, as well as the industrial system and the literacy system. Respectively, their objects are: objects and images, goods and services, and knowledge. (Taborsky, 1981, p. 1) For her, the museum begins to emerge in a recognizable form beginning in the $14^{\text {th }}$ Century.

The museum development of the $14^{\text {th }}, 15^{\text {th }}$, and $16^{\text {th }}$ centuries in Europe...was part of a total structural change involving the whole society and its relations with its environmental units. In the $14^{\text {th }}$ century, society in Europe as a whole began to relate to its environment in a different way from previous eras. This new method, which I could call an 'abstract-and-define' method, involved the removal of environmental units from their natural setting, their collection and storage in a different setting, and their specific naming, definition and analysis (pp. 28-29).

We recognize here the beginning of the Heideggerian trend in the severance of excessive contour and the establishment of fixed identity by means of the production of new integrities, or at least the highlighting of integrities as part of new orders not apparently coordinated with their emergence out of their natural situation.

In the $17^{\text {th }}$ Century, Taborsky points to the collection of John Tradescent as an example indicative of a further development in an overarching trend. The catalogue of this collection from 1656 describes the collection as the "Museum Trandescantianum, or a collection of Rarities preserved at South-Lambeth near London by John Tradescent." Noting several aspects of this description involving authority and history, the idea of a collection as such, the singularity of owner and collector, and the concept of preservation, Taborsky cites an interesting section from further on in the catalogue: "...that the enumeration of these rarities (being more for variety than any one place in Europe could afford) would be an honour to our Nation, and a benefit to such ingenious persons as would become further enquirees into the various modes of Natures admireable workes, and the curious imitations thereof." (p. 31) Taborsky notes, among other points of interest, "the concept that copies could exist of the environmental units." (p. 32) We see here the concept that natural objects are of interest for the sake of their integrities and reproducible identities, rather than for the sake of what Luciano Floridi might point to as an intrinsic value. (Floridi, 2002) Indeed, Taborsky notes that "The origin of the objects and the date of their entry into the collection are not noted." (Taborsky, p. 32)

By the late $17^{\text {th }}$ and $18^{\text {th }}$ Centuries, the trend had moved even further along the trajectory.

The new taxonomic and classifying approach to the world, advocated by such as Bacon, Hobbes, Descartes, Linnaeus and their like, was revealed in the new actions and rights of man to collect, define, and name the environment. Collections were no longer simply conglomerations of mixed units, as had been those of the early individuals, but were being arranged and developed to show particular environmental phenomena, either as defined by man, as in his art works, or as analyzed and created by man, as in the natural and mechanical environment. Collections were being developed to show the environment as something which man could name, define and control.... The collections were now selective and specific, for the objects were collected with a functional goal in mind - as an observable empirical aid to develop and explain scientific theories, not simply as unique curiosities. The units were now 
systematically catalogued to aid in the research, and the objects were used for this research, not for their original function (pp. 34-35).

Denatured items were brought together in order to find patterns of integrities, in order to establish fixed identities, and, moreover, in order to promote and justify the taking of the world as standing-reserve of evidence. The uniqueness and natural contour of the items were irrelevant. Ironically, the provenance of the items was recorded not for the sake of allowing the objects' integrities to point back to their original contours by means of a derived identity, but rather as a means of further enframing the integrities in a system of fixed identities that superseded their original contour.

Following Heidegger we can say then that the activities associated with museums are in no way restricted to the museum, and the birth of museum informatics as the management of information regarding a collection is part of a larger cultural trend that has to do with the extraction of value by means of the severance of natural semiotic radiance and the grounding contours of Firstness. The study of museum informatics as the advance of techniques and technologies for preservation and provision of access is insufficient to frame its own questions. We must move to the level of a fundamental informatics. (Tak-enouchi, 2006; Ohi, 2007; Kolin, 2007)

For Taborsky, the late $19^{\text {th }}$ and early $20^{\text {th }}$ Centuries were a period of consolidation and expansion, during which the range and scope of the museum as such was broadened. (Taborsky, p. 39) One might also argue that it was during this time that the museum, held up as an icon of culture, was also waiting for the culture to catch up with its swift trajectory of Enframing. Indeed, this same period sees both the creation of large public parks, zoos and nature preserves (the creation of which were argued in "Tradescent" terms) and the emergence of an avant garde that rejoiced in both the extremity of its skill in extracting meaning from complexes (Duchamp), even while pointing out this extraction (sometimes in terms of an explicit Marxist critique) through the constrained liberation of antithetical excess (Dada, Surrealism, etc.).

Finally, the trend is extrematized in the mid and late $20^{\text {th }}$ Centuries, during which the "museum is again undergoing a great change in its basic nature, related to the change in the whole social system's methods of relating to the environment." (p. 39) The society at large having caught up to the museum's Enframing, the museum syntax can be extended in a way that remains intelligible, even if strange.

First, it is not only the actual unit which is collected, but increasingly, it is the relationship between the unit and man [sic] which is being collected, analyzed and 'displayed'... [I]t is feelings and actions, the interactions between man and the object, which are in modern times being collected, imagized and stored in photograph, print and tape, as if they were the true image of the unit. This is done in modern museums by 'experience centres', where the stress is on the interaction with the displayed unit. The actual units displayed are only catalysts for those relations. The visitor is expected to experience an interaction between himself and the unit, and the Centre is considered not to properly exist if the visitor cannot or does not have such an interactional experience. The 'experience-centre' is actually a collection not of concrete units, but of relations (pp. 39-40).

In connection with her general argument regarding the immanence of a coherent alignment of cultural syntax, Taborsky sees this same pattern emerging in advertising of the period, where it is the relation to the object, the experience of it, that is sold, not the object itself. The promise of ecotourism in the first decade of the $21^{\text {st }}$ Century could be said to further this argument. It is the experience of integrities and the subjectivization in and around knowledge of integral identities which is collected, an extension of the museum's tendency to collect integrities for the purpose of producing a standing reserve. One quite literally encounters only oneself.

In fact, in some contexts, "the museum visitors are also being collected and analyzed." (p. 39)

...[C]ontrary to the hesitation of early museums to encourage visitors, the modern museums are engaged in their actual collection. The audience is being collected, analyzed and stored, 
as if they were units. They are collected for Special Exhibitions, being gathered specifically for such an exhibition, collected as annual members, as short-term tour groups, as volunteer helpers, and as students. They are being exhibited via reports and attendance records (p. 41).

The people associated with the museum in whatever way have themselves become subject to the enframing propensity, caught up in the informatic labyrinth. They begin to take on identities for themselves formulated not by the authentic encounter between intrinsic contours of semiotic radiance, but by acceptance of synthetic identities framing experience as part of a collective encountering a collection.

Taborsky concludes with a description of the Eco-Museum, which aggregates only identities. "The Eco-Museum, another recent development, emphasizes the collection of data only, leaving the actual units in private on-site ownership. This system sets up the population and the social system of an area, as the contents of the museum. The collection is the people, their relations, the units they make and use. The museum collects what could be considered copies of the collection, via data cards, of the material units and social activities of the region." (p. 41) To quote Heidegger again: "Where Enframing holds sway, regulating and securing of the standing-reserve mark all revealing." (Heidegger, p. 27)

\section{Digital Oblivion}

Taborsky, writing in 1981, did not foresee a final extension of the trend. This is the production of digital museums, an event which could not be conceived until the public adoption of the internet. In fact, the arrival of the virtual has allowed another institution, the library, to continue trends of its own-such as the separation of form and content-to a point of similar abstraction. The result is a kind of convergent evolution such that it is difficult to distinguish between the digital museum and the digital library. The traditional distinction between the two institutions is not without its own difficulties. In a rough sense, one could say that museums seemed to be interested in preserving and making accessible objects in their Firstness, while libraries seemed concerned with the preserving and making accessible of discursive objects in their Secondness.

This distinction is not clean, as in each case the institutions are forced to confront the fullness of the sign, so that, for example, librarians had to be concerned with the preservation and presentation of books and museum workers had to be cognizant of the organization of the manifest informational content of the objects with which they worked. In the case of digital museums, however, the goal is not to present an object in its full contour, but rather to give access to data about that object, including, perhaps, images of that object. In the case of the digital library, one makes available texts and other discursivities in a similarly virtual environment. In both cases, the Firstness of the distinct types of objects is reduced to a "file," the type of object curated in a digital environment.

It would seem that the digital museum has more in common with the digital library, or even a regular library, than with the traditional museum. The distinction is no longer primitive or institutional, but rather discerned in terms of the types of content in a file. The contour of the museum object is supplanted by a more or less fixed system of identification, and the integrity is singularized in the "shot" or "take" (Deleuze, 1986) of the medium used to reproduce the Secondness of the object in the digital museum.

The Secondness of the complex comes to be taken as the Firstness of the digital object, so that the Secondness of the digital object is, in turn, the Thirdness of the original complex. It is the "shot" or "take," which captures a predetermined select integrity or selection of integrities consistent with an articulated identity - which is to say that the content of the virtual reproduction is the specific encounter between a mediated human perception and the object. Like the "experience centre" Taborsky describes, what is collected is the relation, and, as with the collection of museum visitors, the number of visits, or page hits, is counted, held to be of value, and articulated for consumption by others.

Making reference to a digital museum or a digital library, we refer to a pattern of identities. If we "abstract and define" the digital museum and/or digital library as such, furthering the problem situa- 
tion, then we see little difference between a digital museum and a digital library. But the problem of Enframing then becomes intractable, and indifference towards the differences in their coming-to-be serves as a permanent installation of power so that it is difficult to find our way back out of the confounding. If we, however, take the history and context of each into account, we can see that a digital museum and a digital library are outcomes of related but different trends. The first step in overcoming the Enframing of the museum object is then to refuse the confounding of the digital museum and the digital library, to refuse to supplant the history and presence of digital museums and digital libraries with a pattern of identities. We must instead look to the history, traditions, and context of each, recognizing that the distinction made in calling a complex one of these and not the other indicates a difference worth taking into account.

As mentioned, Heidegger refers to the trend to Enframing as a danger. It threatens humanity's freedom by subjecting its natural semiosis to an ordering that deranges experience. This is not subjugation, but the delimitation of truth, such that we proceed without any sensitivity to natural semiosis. Blinded by the concentrated clarity of distilled presence in and as identity-that is, the supplanting of being with meaning-Enframing endangers our existential core by obviating any relation to it. This is in part because Enframing hinders our ability to see past it to the root from which it stems, so that we cannot see the arising of another possibility. Integrity and identity become everything, and the contour of all complexes-the natural coordination of presence in its providing -is forgotten. Integrous identity is the only question, and the only question it asks is after thetic synthesis and the antithetical dissolution of that same. (Hardt \& Negri, 2004, p. 190) But all this is arbitrary, causeless, irrational and based solely on the exercise of power. The danger is oblivion:

Since destining at any given time starts man on a way of revealing, man, thus under way, is continually approaching the brink of the possibility of pursuing and pushing forward nothing but what is revealed in ordering, and of deriving all his standards on this basis. Through this the other possibility is blocked, that man might be admitted more and sooner and ever more primally to the essence of that which is unconcealed and to its unconcealment, in order that he might experience as his essence his needed belonging to revealing (Heidegger, pp. 2526).

If we are to rescue ourselves from this sort of oblivion in general, we must look to recover the contours of reality, the natural semiosis of existence, the natural propensities of experience. We must see the overall patterns of Enframing so that we can choose our relation to it and our participation in it. As a historical trend, it is the outcome of human understanding and action, and as a particular folding of semiotic radiance, it is in keeping with the scope of our experience. We are not subjugated and we can do things differently.

Every destining of revealing comes to pass from out of a granting and as such a granting. For it is granting that first conveys to man that share in revealing which the coming-to-pass of revealing needs. As the one so needed and used, man is given to belong to the coming-to-pass of truth. The granting that sends in one way or another into revealing is as such the saving power. For the saving power lets man see and enter into the highest dignity of his essence. This dignity lies in keeping watch over the unconcealment-and with it, from the first, the concealment-of all coming to presence on this earth.... Enframing comes to pass for its part in the granting that lets man endure-as yet unexperienced, but perhaps more experiences in the future- that he may be the one who is needed and used for the safekeeping of the coming to presence of truth. Thus does the arising of the saving power appear (pp. 32-33).

Heidegger would have us discover that saving power in and through the fine arts, countering techne with poiesis. But it is the fine arts themselves which, through the museum, have become classic examples of the problem at hand. It is not a deployment, but a re-deployment that is needed. We cannot simply produce new semiotic expressions under a different regime. They will be caught up in the Enframing of the museum just as readily as any other has been. Art is not enough, 
enough, and, surely, to turn to art as the savior from technology merely repeats the problem of insisting on subjectivization through a prepurposed artifactuality.

\section{Conclusion: Common Monstrosity}

The trend has historically moved from natural, primitive radiance to the primary extraction of value by enframing, from Firstness to resistant Secondness in the quality of our relations. But it is in the secondary extraction of value, the hacking of the systems of Enframing, the redeployment of relations, that we find Heidegger's saving power. A shift to Thirdness means a furtherance of the trend in some sense, but also a fundamental shift, calling out and amplifying, invoking the extrematized propensities of Secondness that have heretofore constituted the dominant cultural syntax of museums. It means invoking that tendency to the inversion of relations, the latent, haunting impulse in the historical transformation of museums that knows their secret: museums have never been about their collections; they are about us and our relationship to the production of meaning. The emphasis on Secondness as the dominant syntagm for the production of meaning is definitive of the modern era-even in the forms of late capitalist postmodernism which recognize the extremitization of this production under the strains of a highly potentiated inversion. (Hardt \& Negri, p. 190)

Of course, the latent extremity of the postmodern has always existed in some form or another as the possibility of inversion and absurdity. Hardt and Negri point to the emergence in the seventeenth century of "cabinets of monstrosities." (pp. 194-196) But even these operated as signs of possibility, which, while invoking the extremities of Firstness as delineated by the enframing principles of the war machine and modern exercises of eugenic political theologies. It is in Secondness that they emerged as relevant. While appearing to demonstrate a resistance to the extraction of value through severance of contour, they in fact ultimately offer specimens of negativity whose negativity has been extracted for purposes of evaluation and presentation. They present a representation of the monstrous, not an encounter with it-the counterinversion that, while allowing for a discourse that could challenge existing power structures, cooperated in the perpetuation of the basis of the exercise of that power, keeping the regime of Secondness intact. So it is with the opposite extrematization, the postmodern, in which the apparent secondary extraction of value that promises the possibility of an inversion remains within the cultivated order of the (now selfreferential and self-interpreting) sign.

The emergence of the museum can be cast as the emergence of a syntax based not on Firstness and iconicity, but on Secondness and indexicality. If we wish to bring about an inversion to rescue ourselves from the dangers of Enframing, we may perhaps succeed by short-circuiting the signs of its possibility such that we recognize an uncanny presence that has been invoked: the monstrous absurdity of symbolic subjectivization, of Thirdness as a cultural syntagm. This would mean taking up signs of negativity as in the cabinet of monstrosities and exposing them to the corrosive entropic elements of postmodernism, producing a new, symbolic secondary extraction of value that relates directly (where directness is the inversion) to the natural contours of complexes in their Firstness by means of an eccentric Secondness.

The corrosive entropy of the postmodern in this case does not dissolve our relation to reality, but rather the resistance of Secondness. God's eye, which had become the Panopticon, is now a compound eye. The aggregation in the collective no longer has a singularizing subjectivization as its means and end. Rather, it is in the production of a multitude, of a multiplication of subjectivizations, that we can find that hacking which liberates the openness of primitive contour(s) in and as the integrity of a multiplicity of primary extractions.

We have seen that the flesh of the multitude produces in common in a way that is monstrous and always exceeds the measure of any traditional social bodies, but this productive flesh does not create chaos and social disorder. What it produces, in fact, is common, and that common we share serves as the basis for future production, in a spiral, expansive relationship. This is perhaps most easily understood in terms of the example of communication as 
production: we can communicate only on the basis of languages, symbols, ideas, and relationships we share in common, and in turn the results of our communication are new common languages, symbols, ideas, and relationships (pp. 196-197).

Hardt and Negri point us to the Pragmatist notion of "habit" as a first step in understanding this Thirdness as the social form which is flexibly produced and reproduced in interaction with others and which can serve as the malleable, democratic forms of social convocation, but they also argue that while this is a good first take, it remains inside the sphere of modernity and Secondness. As cultural forms, they are taken as signs of community and are thus ritualized to the point of repetition even beyond their natural emergence in primitive radiance. (p. 191)

Moreover, the concept of habit is somewhat limited in scope. "What we need to recognize today instead is a notion of the production and productivity of the common that extends equally from the political to the economic and all the realms of biopolitical production. The productivity of the common furthermore must be able to determine not simply the reform of existing social bodies but their radical transformation in the productive flesh of the multitude." (p. 199) Arguing for the somewhat better concept of performativity, Hardt and Negri point to the queer theory of Judith Butler as a good exemplar. 'Sex is not natural and neither is the sexed body of a 'woman,' Butler explains, but rather like gender they are performed every day, the way the women perform femininity and men masculinity in their daily lives, or the way some deviants perform differently and break the norms." (p. 200) The natural contours of a body are not specific, discernable qualities, but radiate integrities that give rise to perhaps codifiable identities in a natural semiotic radiance.

Performance, like habit, involves neither fixed immutable nature nor spontaneous individual freedom, residing instead between the two, a kind of acting in common based on collaboration and communication. Unlike the pragmatists' notion of habit, however, queer performativity is not limited to reproducing or reforming the modern social bodies. The political significance of the recognition that sex along with all other social bodies is produced and continuously reproduced through our everyday performances is that we can perform differently, subvert those social bodies, and invent new social forms. Queer politics is an excellent example of such a performative collective project of rebellion and creation. It is not really an affirmation of homosexual identities but a subversion of the logics of identity in general. There are no queer bod$i e s$, only queer flesh that resides in the communication and collaboration of social conduct ( $\mathrm{p}$. 200).

Not a freeing up of polymorphous perversity, but an inversion into the radiantly polymorphous in principle.

If the trending of the museum has worked to produce a collective observing a collection, and the saving power of Thirdness resides in the human as Heidegger claims, then we need to generate a new performativity which enacts a secondary extraction of value such that Firstness and Thirdness are recovered from the domain of enframing Secondness. The collective, in relating to a collection, must produce a common. And in order to maintain the continuity of the museum tradition, as well as maintain its character as distinct from that of the library (despite their convergent evolution at the extremities of Secondness), it must build on the trends already in place, performing an inversion, not a severance. As we would expect of Thirdness, it should (re-) mediate our cultural relations, not proliferate a patterning of identities and discernments that sever our relation to the contours of existing circumstance as does Secondness.

Hardt and Negri argue for a new subjectivity, one that is "not sovereign." (p. 208) This arises in and as the multitude which produces its common. They draw an analogy with Mikhail Bakhtin's theory of Dostoyevsky's poetics, in which dialogue "can become an open apparatus in which every subject has equal force and dignity with respect to all others," such that his "novels are great polyphonic apparatuses that create a world in which an open, expansive set of subjects interact and seek happiness." (p. 209) Bakhtin argues "that dialogical narration and polyphonic structure derive from the folklore of carnival and from the carnevalesque vision of the world." (p. 210) The carnevalesque is the horizon upon which the sought transformations can be discovered and explored, cre- 
ated and examined, generated and let loose. It not only allows for the promotion of difference but is defined by it. "The carnevalesque is the prose that opposes monologue and thus refuses to claim an already completed truth, producing instead contrast and conflict in the form of narrative movement itself." (p. 210) But it is not simply that there is no single truth, it is that truth is produced in and as the common that emerges from the polyphony.

In a polyphonic conception of narrative there is no center that dictates meaning, but rather meaning arises only out of the exchanges among all the singularities in dialogue. Singularities all express themselves freely and together through their dialogues create the common narrative structures. Bakhtin's polyphonic narration, in other words, poses in linguistic terms a notion of the production of the common in an open, distributed network structure (pp. 210-1).

This is not just humans transforming their society so as to be liberated in a passive sense, but rather humans rediscovering their own inherent liberation, performing liberation in and as a providingness. In this way, human interaction produces common liberation in the common, where difference is not a constraint on another, but the leading edge of their transcendence. If the trend of history has been humanistic in the sense of the increasing tendency to human control over meaning, value, and experience, then we are describing a kind of post-humanism that is also transcendent of humanism itself, since it is not about controlling these things, but remediating their natural radiance. But this is not a post-humanism that exists in pure continuity with humanism such that it is the "next step" in a progressive history. It operates in an alternative space, that of Thirdness, even while bearing a certain relation to it. The nature of that relation is not one of equivalence, but one of (re-) mediation between (post-) humanism and natural semiotic radiance. It is haunted by itself, by its own possibility, and by its own alterity.

How do we regenerate the space of the museum in common? We must resocialize the space by means of a secondary abstraction of value from the patterning of identities-not only of the objects and the museum, but also of ourselves. We would look to see multiple framings convolving around primary contours, tagged with metadata that enframes identities but also allowing extended folk data of various sorts. One would also want access points discoverable through both a pattern of identification and also through integrities, which latter may or may not include folk data. Moreover, one would want to have these available in some sort of proximal connection to the primary contour.

\section{References}

Buchler, J. (1990). Metaphysics of Natural Complexes (2nd ed.). Albany: SUNY.

Corrington, R.S. (2003). Wilhelm Reich: Psychoanalyst and Radical Naturalist. New York: Farrar, Straus and Giroux. Deleuze, G. (1986). Cinema 1: The Movement-Image. Minneapolis: University of Minnesota Press.

Floridi, L. (2002). On the intrinsic value of information objects and the infosphere. Ethics and Information Technology, 4, 287-304

Foucault, M. (1972). The Archaeology of Knowledge \& The Discourse on Language. New York: Pantheon Books. Hardt, M. \& Negri, A. (2004). Multitude: War and Democracy in the Age of Empire. New York: Penguin Press. Heidegger, M. (1977). The Question Concerning Technology and Other Essays. New York: Harper Torchbooks. James, W. (1996). A Pluralistic Universe. Lincoln: University of Nebraska Press.

Kolin, K. K. (2007). Fundamental Studies in the Field of Informatics: General Analysis, Trends, and Prospects. Scientific and Technical Information Processing, 34(4), 183-189.

McSherry, C. (2001). Who Owns Academic Work?: Battling for Control of Intellectual Property. Cambridge: Harvard University Press.

Ohi, N. (2007). Cognition as Communication: The Accursed Share by Georges Bataille as a contribution to the study of Fundamental Informatics. Retrieved February 14, 2009, from digital-narcis.org: http://www.digitalnarcis.org/ohi/Cognition_as_Communication.pdf

Rowlands, M. (2000). The Environmental Crisis: Understanding the Value of Nature. New York: St. Martin's Press.

Taborsky, E. (1981). The Sociostructural Role of the Museum (PhD Dissertation). Toronto: University of Toronto.

Takenouchi, T. (2006). Information ethics as information ecology: Connecting Frankl's thought and fundamental informatics. Ethics and Information Technology, 8, 187-193. 


\section{About the Author}

Jason T. Hewitt

is a doctoral student at the University of California, Los Angeles, in the Department of Information Studies. His research focuses on the relationship of philosophical skepticism and semiotic theory to information ecologies. He has lectured on the History of Religions, Ecological Theology and Semiotic Ecology at the University of Denver, Naropa University, the Vajrapani Institute, and elsewhere. He works professionally as a consultant and as a Knowledge Manager and Information Architect for MySpace.Com. 